\section{THE BIOLOGICAL EFFECTS OF HEAVY METALS EXPOSURE IN CHILDREN. CLINICAL STUDY}

\author{
S.I. Iurian ${ }^{1,2}$, M.L. Neamtu ${ }^{1,2}$, B.M. Neamtu ${ }^{1,2}$ \\ ${ }^{1}$ Lucian Blaga University, ${ }^{2}$ Pediatric Clinic, \\ Sibiu, Romania
}

Background and aims: To evaluate biological effects secondary to lead and cadmium exposure among children from Copsa Mica county (one of the most polluted areas in Europe during last decades).

Methods: There were analysed 2 groups: first group is represented by 90 exposed children and second group consists in 88 non-exposed children. The both groups were homogenous regarding the age and sex ratios distributions. Inclusion criteria: children between 2-16 years of age, no previous haematopoiesis and kidney diseases. Investigations performed: blood lead level (BLL), cadmium blood level (CBL), ureea and creatinine serum levels, haemoglobin, erythrocytes parameters. Thirtyfive exposed children were tested for urinary alfa1 microglobulin (UA1M). The results were statistically evaluated using Independent-Sample T Test.

Results: BLL mean value in exposed group was $11.15 \mu \mathrm{g} \%$ compared to $1.95 \mu \mathrm{g} \%$ for the second group ( $p$ value $=0.000$ ). The CBL was normal for both groups. There was a significant difference regarding the mean cell hemoglobin concentration - MCHC ( $p$ value $=0.000)$. The ureea and creatinine levels were normal without statistically significant difference between groups. The UA1M values were normal for all tested children.

\section{Conclusions:}

1. The children from Copsa Mica area are still exposed to lead:

2. The study didn't confirm cadmium exposure;

3. There is significant statistical difference for $\mathrm{MCHC}$ in both groups;

4. The UA1M values didn't confirm kidney function impairment even for children with BLL >19 $\mu \mathrm{g} \%$;

5. As compare to previous studies, this study has revealed the reduced impact of heavy metals for health status in exposed children from Copsa Mica.

\section{PSYCHOSOCIAL PARTICULARITIES IN TWO CLINICAL CASES}

\author{
S.I. Iurian ${ }^{1,2}$, M.L. Neamtu ${ }^{1,2}$, B.M. Neamtu ${ }^{1,2}$, \\ B.I. Mehedintu ${ }^{1,2}$, V. Panait ${ }^{2}$ \\ ${ }^{1}$ Lucian Blaga University, ${ }^{2}$ Pediatric Clinic, \\ Sibiu, Romania
}

Background and aims: The authors emphasize the social and psychological peculiarities of 2 children followed in a centre for children with mental and motor disabilities.

\section{Methods:}

First case: 17 years-old boy with particular family history: abandoned child, his mother passed away. Clinical exam revealed short stature, mental retardation, facial dimorphism (sinofris, straight eyebrows), hands anomalies (index finger longer than medius).

Second case: 2 year-old girl with frequent dehydration episodes. The social background: abandoned child, divorced parents.

The clinical exam revealed: growth retardation, clitoral hypertrophy, delay motor skills, mental retardation.

Results: First case investigations have shown: chronic renal failure, secondary anemia, cardiac malformation and polycystic kidneys; the karyotype has identified a duplication of chromosome 2, dup(2) (qter); according to "SkyFISH" method the duplicated fragment belongs to chromosome 4. Laboratory evaluations of second case: hyponatremia, hyperkalemia, metabolic acidosis, hypokaliuria and hypercalciuria; abdominal ultrasound exam revealed enhanced diameters of suprarenal glands; the $17 \mathrm{OH}$ progesterone high levels correlated with deoxycortisol and dehydroepiandrosterone normal values have suggested a salt lost 21 hydroxylase deficit.

Conclusions: The authors have presented the particularities of 2 children with psychological functions impairment and particular social context (abandoned children): the first case with a genetic anomaly and chronic renal failure; the second child with congenital adrenal hyperplasia $(\mathrm{CAH})$ and salt loss. The children peculiarities: even though growth impairment and psycho-motor skills delay could be explained by genetic anomaly (for first case) or $\mathrm{CAH}$ 